\title{
Organização das rotinas na Educação Infantil: contribuições da Teoria Histórico-Cultural para a formação de professores
}

\author{
Organization of routines in Childhood Education: contributions of the Historical- \\ Cultural Theory to the formation of teachers
}

\author{
Organización de rutinas en Educación Infantil: aportes de la Teoría Histórico-Cultural \\ a la formación del professorado
}

Ana Cláudia Bonachini Mendes ${ }^{1}$

\section{Resumo}

Este artigo apresenta como tema contribuições da Teoria Histórico-Cultural para fundamentação de práticas pedagógicas que promovam o desenvolvimento humano na infância. Partimos da premissa de que as práticas intencionalmente organizadas têm potencial para conduzir os processos internos de desenvolvimento das crianças. Tomamos como objeto de estudo a organização do tempo na Educação Infantil com potencial para orientar as ações docentes e experiências vividas pelas crianças na escola da infância. A partir disso, elencamos como objetivo geral: discutir o envolvimento e a participação dessas na organização das rotinas que estruturam os tempos na escola. A investigação aqui apresentada é motivada pela seguinte questão: de que maneira a rotina pode ser organizada a fim de promover o desenvolvimento da autonomia, inteligência e personalidade das crianças que frequentam as escolas de Educação Infantil? Na metodologia da pesquisa, foi elaborado um levantamento bibliográfico em bases de dados digitais para compreensão e aprofundamento teórico do tema. Trata-se de uma pesquisa do tipo intervenção, em andamento, realizada com professores de Educação Infantil de uma escola pública do município de Araçatuba - SP. Ainda que o estudo não apresente resultados finais, os dados analisados revelam a importância da formação continuada para a apropriação teórica do professor e como os estudos compartilhados nos momentos de formação são incorporados aos relatos e práticas das professoras participantes. Palavras-chave: Educação Infantil; Teoria Histórico-Cultural; Formação de professores.

\begin{abstract}
This article presents as theme contributions of the Historical-Cultural Theory to support pedagogical practices that promote human development in childhood. We start from the premise that intentionally organized practices have the potential to drive the internal processes of children's development. We take as an object of study the organization of time in Early Childhood Education with the potential to guide the teaching actions and experiences of children in the childhood school. From this, we list as a general objective: to discuss the involvement and participation of these in the organization of the routines that structure the times at school. The investigation presented here is motivated by the following question: how

\footnotetext{
${ }^{1}$ Mestre em Educação. Doutoranda do PPGE da UNESP-Marília-SP. Professor Adjunto II no UniToledo, Araçatuba-SP. Diretora de escola Municipal de Educação Infantil, Araçatuba-SP. ORCID: https://orcid.org/0000-0003-2714-8008. E-mail: bonachini.thc@ gmail.com
} 
can routine be organized in order to promote the development of autonomy, intelligence and personality of children who attend Kindergarten schools? In the research methodology, a bibliographic survey was elaborated in digital databases for theoretical understanding and deepening of the theme. This is an intervention-type research, in progress, carried out with Kindergarten teachers from a public school in the city of Araçatuba - SP. Although the study does not present final results, the data analyzed reveal the importance of continuing education for the theoretical appropriation of the teacher and how the studies shared in the training moments are incorporated into the reports and practices of the participating teachers.

Keywords: Early Childhood Education; Historical-Cultural Theory; Teacher training.

\section{Resumen}

Este artículo presenta como tema los aportes de la Teoría Histórico-Cultural para apoyar las prácticas pedagógicas que promueven el desarrollo humano en la niñez. Partimos de la premisa de que las prácticas organizadas intencionalmente tienen el potencial de impulsar los procesos internos del desarrollo infantil. Tomamos como objeto de estudio la organización del tiempo en Educación Infantil con el potencial de orientar las acciones y experiencias docentes de los niños en la escuela infantil. A partir de esto, enumeramos como objetivo general: discutir la implicación y participación de estos en la organización de las rutinas que estructuran los tiempos en la escuela. La investigación que aquí se presenta está motivada por la siguiente pregunta: ¿cómo se puede organizar la rutina para promover el desarrollo de la autonomía, la inteligencia y la personalidad de los niños que asisten a las escuelas de jardín de infancia? En la metodología de la investigación se elaboró un relevamiento bibliográfico en bases de datos digitales para la comprensión teórica y profundización del tema. Se trata de una investigación tipo intervención, en curso, realizada con profesores de jardín de infancia de una escuela pública de la ciudad de Araçatuba - SP. Si bien el estudio no presenta resultados finales, los datos analizados revelan la importancia de la educación continua para la apropiación teórica del docente y cómo los estudios compartidos en los momentos de formación se incorporan a los informes y prácticas de los docentes participantes.

Keywords: Educación Infantil; Teoría Histórico-Cultural; Formación de profesores.

\section{Introdução}

A Teoria Histórico-Cultural explica que o sujeito aprende e se desenvolve a partir das relações e interações que estabelece com o outro e com o meio. Nesse processo de apropriação de regras, de comportamentos sociais e dos conhecimentos culturais produzidos ao longo da história, o sujeito se humaniza. Ou seja, é na relação com o outro que adquirimos as qualidades especificamente humanas que nos diferencia dos outros animais. Nessa perspectiva, Vygotski (2000) nos ensina que o aprendizado é um aspecto necessário e universal no processo de desenvolvimento das funções psicológicas superiores (FPS) percepção, atenção voluntária, memória, abstração, pensamento e linguagem - que formam a inteligência e personalidade humana. Assim, sua teoria nos fornece elementos teóricos e científicos para a compreensão de que o desenvolvimento das FPS é mediado socialmente 
pelos signos e pelo outro. É importante esclarecer também que nem toda aprendizagem promove o desenvolvimento, por esta razão, é necessário avaliar sob quais condições a aprendizagem opera, de fato, a serviço do desenvolvimento dos indivíduos tendo em vista que a conquista do pensamento sofisticado não depende somente dos esforços individuais das crianças, mas essencialmente do contexto no qual elas estão inseridas.

É válido ressaltar que, "não são quaisquer modelos pedagógicos que se colocam efetivamente a serviço do desenvolvimento psíquico" (MARTINS, 2013, p. 270), ora, se nem todas as aprendizagens propiciadas às crianças são capazes de promover o desenvolvimento psíquico delas, cabe aqui uma reflexão para pensarmos sobre os princípios de uma prática pedagógica promotora do desenvolvimento humano e sobre os possíveis impactos de proposição de práticas enriquecidas de sentido para as crianças.

Com essas considerações iniciais, elencamos como objeto de estudo a organização do tempo na Educação Infantil (EI). A inspiração para esta reflexão surgiu a partir dos estudos de Silva (2017) ao destacar que os modos de organização do tempo e das rotinas podem potencializar as ações docentes e as experiências vividas pelas crianças na escola da infância, adotando a perspectiva de que é possível pensar as ações cotidianas e ao mesmo tempo promover novas experiências para elas. Nas palavras da autora, "ao organizar a rotina coletivamente consideramos a necessidade de organizá-la de forma que as experiências vivenciadas pelas crianças na escola promovam o desenvolvimento das máximas qualidades humanas". (SILVA, 2017, p. 146)

Considerando que as formas de organização do tempo e das rotinas na escola revelamse como possibilidades de aprendizagem e desenvolvimento humano na infância e que as práticas educativas são organizadas pelos adultos, esta reflexão propiciou a elaboração da seguinte da seguinte questão: de que maneira os processos de formação continuada podem ampliar a compreensão sobre a organização do tempo e das rotinas com a finalidade de promover o desenvolvimento da autonomia, inteligência e personalidade das crianças que frequentam as escolas de Educação Infantil?

Partimos do princípio de que as práticas pedagógicas que se propõe para as crianças, podem e devem assumir o caráter de impulsionadoras do desenvolvimento infantil, para tanto, as ações e intenções dos professores precisam pautar-se na teoria e na ciência. Ou seja, para planejar, precisamos compreender como a criança aprende e se desenvolve, "com esses pressupostos, falamos em educação desenvolvente, ou seja, uma educação intencionalmente 
organizada para impulsionar positivamente o desenvolvimento infantil. " (MELLO e FARIAS, 2010, p.55)

Motivadas pelas descobertas na breve caminhada pela Teoria Histórico Cultural, primeiramente, destacamos alguns desencontros entre o que propõe as orientações oficiais sobre a organização do trabalho pedagógico na EI e o que ocorre na prática, bem como as implicações pedagógicas para o desenvolvimento infantil. Todavia, a partir da revisão de literatura sobre o tema, destacamos algumas possibilidades de reencontros com uma prática cientificamente fundamentada e com possibilidades de superação dos obstáculos e desafios do dia a dia do trabalho do professor. Na sequência, apresentamos a análise dos dados obtidos na pesquisa realizada em uma escola municipal de EI no município de Araçatuba-SP, na qual foi possível constatar e compreender as possibilidades de entrelaçamento da teoria com a prática propiciadas a partir dos estudos realizados nos momentos de formação continuada com as professoras da escola. Nas considerações finais, pontuamos três dimensões que podem ser estruturadas a partir das especificidades da docência na primeira infância.

\section{Rotinas na educação infantil: alguns desencontros}

As Diretrizes Curriculares Nacionais para a Educação Infantil (BRASIL, 2009) determinam que a proposta pedagógica das instituições de EI deve ter como objetivo garantir à criança acesso a processos de apropriação e articulação de conhecimentos e aprendizagens de diferentes linguagens. Para o alcance desse objetivo, as instituições de EI deverão prever condições para o trabalho coletivo e para a organização de materiais, espaços e tempos. $\mathrm{Ou}$ seja, a aprendizagem e o desenvolvimento das crianças também estão condicionados à maneira como organizamos os espaços, tempos, materiais e sobretudo, as relações sociais que estabelecemos com elas.

Entretanto, no dia a dia das escolas de EI, as dimensões - tempo, espaço, materiais e relações sociais - são estruturadas e padronizadas em uma rotina que segue a lógica do adulto e que pouco a pouco, regulam os ritmos individuais e coletivos das crianças. Pesquisas sobre o cotidiano escolar nas escolas de EI revelam que há indícios de que as atividades são propostas para o grupo de crianças sem levar em consideração seus ritmos individuais, gostos ou preferências. Todas as crianças são levadas a desenvolver ao mesmo tempo e no mesmo 
espaço uma mesma atividade proposta pela professora. Trabalha-se com uma suposta homogeneidade e uniformidade dos comportamentos das crianças. (BATISTA, 1998)

Em muitas práticas educativas destinadas à pequena infância, as rotinas são definidas pela Secretaria de Educação e pela escola sem considerar a participação das crianças. Além disso, não se compartilham com elas explicações ou exposição dos motivos que definem as rotinas da escola. (RIBEIRO, 2009; SILVA, 2017)

Há ainda os casos em que a organização das rotinas escolares é elaborada pelos gestores da instituição com pouca participação dos docentes. Percebe-se a ausência nos planejamentos das ações pedagógicas, o que limita a participação das crianças nas situações propostas. A partir da análise do discurso dos docentes e observação da prática, é possível identificar uma ruptura entre a organização do tempo institucional e o tempo individual da criança, justamente por não se considerar as particularidades infantis. (PRIETO, 2016)

De modo geral, o tempo institucional é estruturado por meio de rotinas para garantir o funcionamento da escola e a organização do trabalho pedagógico do professor. No que se refere ao funcionamento da instituição, os horários de entrada e saída das crianças, horários de alimentação, higiene pessoal e sono, são definidos a partir dos turnos de trabalho dos funcionários e jornadas dos professores que ali trabalham. Nos aspectos referentes ao trabalho do professor, as rotinas aparecem como modelos, listas ou sugestões de forma pouco ou nada fundamentadas, tornando-se apenas uma prescrição do que deve ser realizado, o momento adequado para executar as atividades e os espaços e materiais que serão utilizados. (BARBOSA, 2006; VIEIRA, 2000).

O tempo institucional como objeto de análise, configura-se como uma categoria socialmente construída que envolve a subjetividade individual e o conjunto de significados culturais e sociais. Todavia, a ordem temporal normativa das instituições escolares e a ordem simbólica das subjetividades individuais são sistemas que não se comunicam, isto é, o tempo institucional difere dos tempos de aprendizagem e desenvolvimento das crianças. (FRAGO, 1995; NIGITO, 2004). Nessa perspectiva, os autores reforçam a necessidade de compreendermos como a organização institucional do tempo pode influenciar as vivências e experiências infantis, uma vez que essa organização se constitui como um contexto formador que veicula atitudes, hábitos e esquemas de comportamento.

A partir dessa breve análise crítica do problema percebemos que há um desencontro entre o que propõe o ordenamento legal e o que efetivamente ocorre na prática. Como 
profissionais intelectuais precisamos ter consciência da importância do nosso trabalho que é "refletir, selecionar, organizar, planejar, mediar e monitorar o conjunto das práticas e interações, garantindo a pluralidade de situações que promovam o desenvolvimento pleno das crianças.” (BRASIL, 2017, p. 39).

Para tanto, precisamos reunir elementos teóricos e científicos para reorganizar tempos, espaços e relações sociais que garantam os direitos de aprender e se desenvolver de todas as crianças. Com isso pontuamos que, quando organizamos as dimensões educativas - tempos, espaços, materiais e relações sociais - a partir de sua função social, isto é, compartilhando com as crianças o que justifica a organização temporal do que acontece na escola, orientando o uso e organizando os espaços e materiais com a ajuda das crianças e por fim, estabelecendo com elas relações sociais nas quais possam participar como sujeitos ativos e pensantes, criamos as condições concretas de desenvolvimento das qualidades psíquicas humanas - FPS, que formam sua personalidade e inteligência.

\subsection{Rotinas na educação: possibilidades de encontros}

A atividade docente é uma dessas atividades em que as possibilidades de desenvolvimento da individualidade podem estar colocadas ao máximo: ao educador cabe avaliar as condições do trabalho que enfrenta e, com base nessa avaliação eleger as metas que respondam ao mesmo tempo, aos fins necessários, às condições concretas existentes para realização desses fins e aos valores com os quais o educador se acha comprometido. (MELLO, 2000, p.99)

As colocações do excerto acima, nos encoraja a compreendermos que as possibilidades para superar os obstáculos colocados pelas condições concretas de vida - às quais estamos submetidos - estão condicionadas à apropriação teórica do professor. Ou seja, quando nós, professores e professoras, nos tornamos conscientes da responsabilidade social da nossa atividade como profissionais intelectuais, as necessidades e dificuldades que emergem da prática educativa constituem-se em objetos de estudo e análise para a superação dessa e não para o seu impedimento.

Considerando que o tempo institucional das escolas precisa ser instituído, pelas razões já expostas, é possível pensarmos em um modo de organização que possibilite uma maior flexibilização das tarefas já estabelecidas, pois, a rotina não precisa ser rígida e nem limitada. 
Ela também pode ser rica, alegre, prazerosa e sobretudo, considerar as especificidades da infância proporcionando momentos de interação e socialização. (JESUS, 2013).

Para Silva (2017, p. 142), “A organização da rotina exige que seja considerada não somente as demandas da instituição quanto ao seu funcionamento, mas principalmente que se considere a aprendizagem e o desenvolvimento das crianças". No mesmo sentido, Jesus, (2013) afirma que:

[...] é essencial que o professor, bem como todos os profissionais envolvidos nesse trabalho, tenha suas práticas fundamentadas em concepções que contribuam para o desenvolvimento integral da criança na educação infantil, de modo que a organização da rotina possua objetivos e o professor projete ações em que se proporcionem a criança novas e ricas experiências para conhecer, explorar, imitar e, portanto, se desenvolver. (JESUS, 2013, p.31)

Portanto, a organização do tempo na EI será de qualidade quando estiver organizado a partir de uma rotina que atenda às necessidades da instituição e às necessidades das crianças pequenas. A participação ativa das crianças na elaboração das rotinas proporciona a noção e a compreensão do tempo, oportunizando o desenvolvimento da autonomia. (PIRES; MORENO, 2015). Logo, ao integrar a criança na elaboração da rotina escolar, ela se sente parte integrante e motivada a querer participar das atividades estabelecidas.

Os estudos sobre a criança e sua aprendizagem pautados nos pressupostos da Teoria Histórico Cultural, demonstram que a apropriação das qualidades tipicamente humanas não ocorre naturalmente com o advento do nascimento. Essas qualidades humanas são frutos das vivências e das relações sociais das quais as crianças participam, filtrados pelo sentido que elas atribuem para tais experiências. Isto é, a partir das condições pedagógicas criadas para a constituição dessas FPS, as crianças formam sua inteligência e personalidade. Portanto, o aprimoramento de tais funções é resultado de um processo de aprendizagem, pois, são as experiências vividas pelo sujeito que impulsionam o seu desenvolvimento. (JESUS, 2013)

Nessa perspectiva teórica, a criança é compreendida como um sujeito ativo, pensante e dotada de capacidade para participar de maneira competente do seu próprio processo de aprendizado e desenvolvimento, tendo em vista que ela é parte do meio vivo, esse meio nunca é externo a ela. "Si el niño es un ser social y su medio es el medio social, se deduce, por tanto, que el propio niño es parte del entorno social.” (VYGOTSKI, 1996, p. 382). Logo, a visão de criança defendida por esta Teoria implica a transformação das práticas educativas tradicionais que enxergam a criança como um ser frágil, imaturo ou incapaz. 
A teoria histórico-cultural enfatiza a natureza social do ser humano, o desenvolvimento da inteligência, da personalidade e da conduta humana. Para essa teoria o ser humano não nasce humano, mas aprende a ser um ser humano a medida que atua sobre a realidade e se apropria da conduta humana - o conjunto de produção humana - e a transforma. (SILVA, 2017, p.144)

Compreender que o ser humano se humaniza ao atuar sobre a realidade e na relação com seus pares, pressupõe que a educação é um processo de humanização. Vygotski (2003) nos ensina que, para educar é preciso organizar a vida, mais precisamente o meio social. Assim, tomando-se como referência o contexto da escola da infância, são os adultos que organizam o meio social. À vista disso, no que se refere ao desenvolvimento da personalidade e inteligência das crianças,

[...] o meio se apresenta como fonte de desenvolvimento para as formas de atividade e das características superiores especificamente humanas, ou seja, exatamente a relação com o meio é a fonte para que surjam essas características na criança. Se essa relação for violada por força de circunstâncias inatas da criança, as características superiores não surgirão. (VYGOTSKI, 2018, p. 90)

Nesse sentido, afirmamos que a organização do meio social implica a responsabilidade e a intencionalidade de nós, professores e professoras, em promover vivências nas quais as crianças possam: explorar e descobrir diversos materiais; criar e expressar-se por meio das múltiplas linguagens presentes no cotidiano infantil; compartilhar ideias com os amigos e com os adultos; colaborar e cooperar de forma solidária com os amigos nas situações cotidianas; sugerir e participar ativamente da rotina que será estabelecida para o dia; analisar e avaliar sua própria conduta a partir de metas estabelecidas, seja para o dia/semana/ou mês; e sobretudo, compreender as razões que regulam a organização dos espaços, materiais e tempos na escola. Assim sendo, “o máximo desenvolvimento humano na infância não depende somente da educação que as crianças recebem na escola da infância, mas também de suas condições objetivas de vida. " (TEIXEIRA; BARCA, 2017, p. 39)

\subsection{Contribuições da Teoria Histórico-Cultural para a formação de professores}




\section{OO DEVIR EDUCAÇÃO}

ISSN: 2526-849X

Compreender o papel da educação e a organização das condições do meio social para a apropriação das máximas qualidades humanas na infância, exige do professor a formação pensada e orientada para essa finalidade. "Ela possibilita o entrelaçamento entre a teoria e a realidade de estudo, como um procedimento reflexivo e sistemático, controlado e crítico, que permite descobrir novos fatos ou dados, relações e leis em qualquer campo de conhecimento." (PACHECO et al., 2013, p. 302). Isto é, a formação a partir de um dado contexto, revela-se como um instrumento de desvelamento da realidade, com princípios orientadores para a compreensão e possibilidades de intervenção no cotidiano. Desse modo, o professor terá elementos para organizar seu trabalho de modo a promover o máximo desenvolvimento humano na infância.

A creche e escola da infância podem e devem ser o melhor lugar para a educação das crianças pequenas - crianças até os 6 anos - pois aí se pode intencionalmente organizar as condições adequadas de vida e educação para garantir a máxima apropriação das qualidades humanas - que são externas ao sujeito no nascimento e precisam ser apropriadas pelas novas gerações por meio de sua atividade nas situações vividas coletivamente. (MELLO, 2007, p. 12).

A compreensão de que as qualidades humanas não são dadas naturalmente reforça a importância primordial do papel da escola para esta Teoria. Logo, se as qualidades humanas são aprendidas nas relações sociais, isso implica a atividade intencional do professor embasada nos conhecimentos das regularidades do desenvolvimento biológico e cultural dos seres humanos.

\section{Método}

Para configuração deste artigo, foi elaborada uma revisão de literatura nos portais e periódicos recomendados pela Coordenação de Aperfeiçoamento de Pessoal de Nível Superior (CAPES), pontuando-se os enfoques das pesquisas sobre a temática. No meio acadêmico essa atividade da pesquisa é conhecida como estado da arte, compreendida como, "uma contribuição importante na constituição do campo teórico de uma área de conhecimento, pois procuram identificar os aportes significativos da construção da teoria e prática pedagógica, apontar as restrições sobre o campo em que se move a pesquisa." (ROMANOWSKI; ENS, 2006, p. 39) 
$\mathrm{Na}$ continuidade dessa pesquisa-intervenção, foi elaborado um roteiro de estudos pautados na Teoria Histórico Cultural para a organização da prática pedagógica e promoção do máximo desenvolvimento humano na infância. O roteiro contemplou diversos elementos teóricos e científicos para a organização do trabalho pedagógico. Entretanto, pelo fato de a pesquisa $^{2}$ estar em andamento, serão apresentados apenas os dados referentes aos estudos que tiveram como objetivo discutir o envolvimento e a participação das crianças na organização das rotinas que estruturam os tempos na escola da infância. Desse modo, serão destacados os relatos de três (3) professoras atuantes na escola e que trabalham com crianças de 4 e 5 anos. As professoras participantes da pesquisa foram identificadas como: P1, P2 e P3, como forma de garantia de anonimato e por questões éticas da pesquisa.

Durante o ano de 2020, iniciamos os estudos nos Horários de Trabalho Pedagógico Coletivo (HTPC) de forma presencial em fevereiro. A partir de março, devido às circunstâncias impostas pela Pandemia da COVID- $19^{3}$, passamos a realizar os estudos de maneira remota utilizando a plataforma Google Meet.

O plano de formação contemplou a leitura e discussão de trinta (30) textos, exibição de quatro 4 vídeos e análise em conjunto das práticas pedagógicas das professoras participantes. Assim sendo, os estudos realizados durante os meses de fevereiro a novembro de 2020 totalizaram sessenta e duas horas. Após a transcrição literal das discussões sobre o tema específico de participação das crianças na organização das rotinas, foi possível organizar os relatos das professoras nas seguintes categorias de análise: planejamento do professor a partir da organização dos tempos e espaços institucionais; envolvimento e participação das crianças na organização da rotina e a relevância da formação em contexto para desenvolvimento humano na infância.

\section{- $\quad$ Planejamento do professor a partir da organização dos tempos e espaços}

institucionais - As questões relacionadas a essa categoria de análise revelaram elementos

\footnotetext{
${ }^{2}$ Os estudos realizados com as professoras da referida escola constituem-se uma das fases da pesquisa em andamento que tem como objeto de estudo as implicações da Teoria Histórico Cultural para formação de professores da Educação Infantil. Esta pesquisa em nível de doutorado está vinculada ao Programa de PósGraduação em Educação da Unesp, Campus de Marília - SP, na linha de pesquisa "Teoria e Práticas Pedagógicas".

${ }^{3}$ A COVID-19 é uma doença causada pelo Coronavírus, denominado SARS-CoV-2, que apresenta um espectro clínico variando de infecções assintomáticas a quadros graves. Em 11/03/2020 a Organização Mundial da Saúde (OMS) elevou a classificação do novo Coronavírus para pandemia. Fonte consultada: https://www.gov.br/ptbr/noticias/saude-e-vigilancia-sanitaria/2020/03/oms-classifica-coronavirus-como-pandemia.
} 
para a compreensão sobre como as professoras organizam o planejamento a partir das condições objetivas estabelecidas para o funcionamento da escola. A esse respeito, as professoras P1, P2 e P3 afirmaram que na escola onde lecionam, a equipe gestora, as docentes e as educadoras, elaboraram um cronograma ${ }^{4}$ que organiza os tempos e os espaços da escola, com o propósito de garantir que todas as turmas possam utilizar-se dos espaços da escola nos tempos demarcados para não haver improvisos. Relatam ainda que o cronograma organizado possui uma estrutura flexível, visto que as professoras podem negociar entre si, quando necessário. A P1 mencionou que:

[...] eu achei muito interessante essa escola, porque que eu nunca tinha trabalhado lá. E eu achei legal o horário que elas fazem com vários momentos fora da sala de aula e tudo muito bem organizado, sabe que eu tenho um dia de areia outro dia eu tenho de parede de azulejo, e assim as turmas não se chocam, então você tem como todos os dias oferecer para a criança um ambiente diferente. (P1)

Levando em consideração essa e outras falas das professoras, é possível compreender que a gestão tem um papel fundamental na organização do tempo e do espaço nas escolas de EI, uma vez que contribui para a qualidade do trabalho docente e o oferecimento de espaços diversos para a exploração e a descoberta das crianças.

Em relação ao planejamento das atividades, a P1 afirmou que o tempo é organizado de acordo com a proposta da aula. Além disso, ressalta a importância de conhecer as crianças para a organização do tempo, já que as aprendizagens individuais ocorrem em tempos distintos. Também se faz necessário que sejam pensados: a quantidade de atividades, o tempo necessário para a execução destas e o ritmo de aprendizagem das crianças, a fim de atingir uma aprendizagem de qualidade. A P2 relatou que organiza seu planejamento conforme os objetivos e expectativas elencados para a semana. E a P3 nos descreveu que:

A organização do tempo é pré-estabelecida por mim... no momento em que estou preparando a aula. E seguindo a rotina escolar, eu vou planejando de acordo com a atividade com a rotina escolar, porém ele é relativo, é porque depende do grau do interesse das crianças, então conforme a aula vai acontecendo eu vou observando, vou analisando, e aí o quanto tá sendo

\footnotetext{
${ }^{4} \mathrm{O}$ referido documento institucional é estruturado em forma de tabela e contempla os diferentes espaços que podem ser explorados pelas crianças junto com os professores: tanque de areia, solário, parque, sala da recreação, biblioteca, ateliê, paredão de giz (lousa grande localizada na área externa), parede de azulejos e estação de águas (chuveirão). O cronograma é semanal e as professoras podem usar os espaços, por um tempo de 30 minutos se assim desejarem.
} 
produtivo esse tempo pra eles, esse tempo é, pode ser é, aumentado ou diminuído, depende do grau do interesse das crianças, né, então, dentro dessa dinâmica eu busco auxiliar o tempo, entre o interesse e o tempo disponível que nós temos na rotina da escola. (P3)

\section{- $\quad$ Envolvimento e participação das crianças na organização da rotina - No} que se refere a essa categoria de análise, as professoras P1, P2 e P3 têm discursos semelhantes, pois relatam que as crianças participam do planejamento por meio de diálogos com o propósito de discutir com os alunos seus interesses, suas ideias, seus questionamentos, bem como suas curiosidades. Além disso, P1 e P2 mencionam que o planejamento pode ser repensado junto às crianças, a fim de se fazer as devidas mudanças. A professora P3 comenta que a aula ocorre de acordo com o interesse e curiosidade da turma. Assim, quando surgem novas ideias propostas pela turma a aula flui de maneira diferente do que foi planejada inicialmente. Em suas palavras, a docente ainda comenta que as crianças:

[...] são o centro do planejamento... as crianças que norteiam o planejamento das aulas. De acordo com o que eu observo em relação ao interesse deles, conforme eles vão expressando, suas ideias e suas curiosidades durante a nossa convivência, eu vou adequando o planejamento. (P3)

Diante do exposto nas respostas das professoras é possível perceber que as crianças têm possibilidades de participarem das ações de planejamento, seja na fase prática ou até mesmo para os planejamentos das próximas aulas. Nessa perspectiva, Mello et al. (2017) contribui dizendo que

Cada atividade pode ser apresentada às crianças sob a forma de convite à sua realização. À medida que as crianças se expressam por meio da fala, já será possível envolvê-las nas elaborações do plano do dia, quando nós, professoras e professores, apresentamos nosso plano de atividades no início do dia, iniciando sempre por uma pergunta convite à participação: "O que vamos fazer hoje?". Quando damos a conhecer o nosso plano de atividades, estamos envolvendo as crianças no processo de planejamento diário. Quando trabalha assim, logo percebemos que a participação das crianças pode ser ampliada com sugestões de atividades pela própria criança. (MELLO et al., 2017, p. 220).

Portanto, por meio da análise dos relatos das professoras é possível inferir que elas compreendem a importância de envolver as crianças no planejamento do dia-dia escolar, visto 
que essa participação pode contribuir para um trabalho mais significativo e de qualidade. $\mathrm{Ou}$ seja, com potencial para o pleno desenvolvimento das qualidades humanas na infância.

Com relação à participação das crianças na organização da rotina, as professoras $\mathrm{P} 1$, P2 e P3 falam que a organização da rotina escolar é pensada, discutida e socializada no início do dia junto com as turmas, por meio de desenhos confeccionados por eles. Esses desenhos são a representação de cada momento da rotina. A P1 utiliza todos os desenhos das crianças, sem que seja feita nenhuma seleção, relatando que "todo mundo tem a participação em todos os desenhos". Já a P2 relata que as crianças fazem o desenho e realizam uma eleição para eleger um desenho a representar cada atividade do dia, ela também relata que as crianças cobram quando algo atrapalha a execução da rotina. A P3 utiliza-se dos desenhos das crianças maiores, já com as turmas de crianças menores, utiliza fotografias de cada momento. Para compartilhar a rotina com as crianças, as professoras iniciam o dia com a colaboração das crianças para organização das placas que representam as atividades de rotina. Em relação à organização da rotina representada pelas placas, a P3 relata que

[...] organizamos no início do dia enquanto estou falando da rotina, nós já vamos colocando na sequência as atividades que serão realizadas, e é muito interessante, porque eles se baseiam, eles utilizam esse material de apoio, essa organização. O tempo todo, eles observam, eles fazem as colocações deles, e isso é muito importante. (P3)

Nessa perspectiva, as professoras demonstraram organizar um trabalho que possibilita o envolvimento e a participação das crianças na elaboração e cumprimento das rotinas. Visto que esse trabalho junto a elas pode contribuir para que desenvolvam a noção de tempo, de espaço em situações de uso legítimo dos marcadores que regulam e estruturam os tempos institucionais. Pires e Moreno (2015) reforçam nossas colocações afirmando que,

[...] organizar a rotina com as crianças proporciona noção e compreensão de tempo, além de desenvolver o papel ativo na construção deste contexto. Os ambientes devem possibilitar expressões e linguagens das crianças, convívio e diversidade, valores, construção da identidade, cooperação e autonomia. (PIRES; MORENO, 2015, p.41654).

Dessa maneira, quando envolvemos as crianças na organização da rotina escolar estamos dando voz e vez a elas, proporcionando uma participação ativa, significativa e potencializadora de aprendizagem. Assim, se a construção da noção de tempo na escola da 
infância e o modo como as crianças vivenciam esse tempo for respeitada, as vivências se tornarão possibilidades para o pleno desenvolvimento humano na infância. (PIETRO, 2016)

- Relevância da formação em contexto para desenvolvimento humano na infância - Sobre a partilha de ideias, as professoras mencionaram que os momentos de formação continuada são sempre mediados pela equipe gestora, o que tem possibilitado a compreensão e o enriquecimento de suas práticas. As professoras relataram que em situações de troca de ideias com os pares, elas têm aprimorado a compreensão sobre a importância da participação das crianças na organização das rotinas. A professora P2 mencionou que a ação de partilhar com as crianças a organização da rotina possibilita o desenvolvimento da autonomia e noção temporal das crianças. Na opinião da professora P3, é relevante envolver as crianças porquê reduz a ansiedade, isto é, ao compartilhar com elas sobre o que irá acontecer cria-se condições para que compreendam a organização do dia e se apropriem da cultura da escola ao mesmo tempo em que desenvolvem a noção temporal.

As discussões e reflexões compartilhadas no grupo de professoras revelaram que a participação e o envolvimento das crianças na organização das rotinas constituem-se como possibilidades de desenvolvimento e formação das qualidades humanas, no contexto da educação na infância. De maneira geral, as professoras já realizavam essa ação com as crianças, no entanto, elas pontuaram que os estudos têm ampliado a visão sobre as possibilidades de enriquecimento das vivências das crianças na escola da infância.

Compreender o papel do professor como responsável pela organização do tempo, espaço e relações sociais, implica compreender as especificidades da docência na EI e de que maneira as práticas podem ser intencionalmente organizadas para este fim.

Para uma concepção histórico-cultural do ser humano - para a qual as características humanas são aprendidas -, a intencionalidade do/a professor/a orientada pelo profundo conhecimento das regularidades do processo de desenvolvimento biológico e cultural, e dirigida para a apropriação das máximas qualidades humanas é condição essencial, ainda que não suficiente, para a formação das marcas do humano nas crianças (MELLO, 2019, p. 2).

Nesse sentido, a compreensão do desenvolvimento humano na infância está vinculada aos processos de formação em contexto e por esta razão, as práticas formativas devem articular-se com as situações cotidianas profissionais e os saberes docentes devem ser compartilhados e discutidos à luz da Teoria Histórico Cultural. Logo, se no processo de 
formação em contexto o professor tem um papel ativo na construção de seus saberes, consequentemente o resultado dessa ação terá implicações na vida das crianças.

\section{Resultados e discussões}

No decorrer da reflexão, analisamos e discutimos o envolvimento e a participação das crianças na organização das rotinas na EI como possibilidades de desenvolvimento da autonomia, inteligência e personalidade sob a luz da Teoria Histórico-Cultural. Nessa perspectiva teórica, a Educação tem papel fundamental para a formação humana no sentido amplo - processos que ocorrem nos círculos familiares e sociais em geral - e no sentido restrito - processos que ocorrem especificamente na escola.

Considerando que na escola podemos organizar as ações educativas de modo intencional, isto é, para a apropriação das máximas qualidades humanas, apresentamos três dimensões que podem ser (re) pensadas e refletidas a partir das especificidades da docência na EI, são elas:

a) O tempo na perspectiva da criança - o tempo institucional é uma construção social pensada e elaborada para normatizar o funcionamento da escola e o tempo da criança é uma construção simbólica individual, mas, nem sempre o tempo da criança dialoga com o tempo institucional. Assim, para reduzir essa distorção e amenizar os impactos negativos para o desenvolvimento infantil, nós, professores e professoras, podemos organizar o tempo que as crianças passam na escola de modo a garantir: a partilha de informações sobre como e por que organizamos as rotinas; o envolvimento e a participação delas da organização do tempo, espaços e materiais; diferentes formas de organização de tempo para execução das atividades; diversas propostas de agrupamentos: coletivos, em duplas e individuais, pois, como já foi dito, as crianças têm ritmos diferentes de aprendizagem. Com essa forma de organização, constatamos a diminuição do nível de ansiedade das crianças, uma vez que se autorregulam na execução das atividades planejadas. Com a descentralização do trabalho do professor, há uma considerável redução do tempo de espera, pois, as crianças podem fazer atividades diferentes de acordo com seu ritmo de aprendizagem. E, por fim, ao se anteciparem a respeito do que foi planejado para o dia, elas se apropriam das noções de tempo e espaço, pautadas em relações sociais plenas de sentido para elas. 
b) Formação continuada do professor - o planejamento das ações pedagógicas voltadas para as especificidades da EI, exige de nós, professores e professoras, formação teórica e científica para sermos intelectuais de nossa própria prática. Isto é, o ato de planejar, pensar, registrar, executar, avaliar e transformar as nossas práticas com as crianças, precisa pautar-se na teoria e na ciência. Portanto, para organizar o trabalho educativo fundamentado em processos culturais de desenvolvimento e aprendizagem adequados às crianças pequenas, é indispensável que o professor tenha acesso a espaços de aprendizagem, de reflexões e de pertença por meio de uma postura contínua de aprendiz, que terá como resultados análogos ver-se em uma determinada cultura de aprendizagem e desenvolvimento. (GOMES, 2013)

c) Gestão escolar - a dimensão da gestão escolar também tem papel fundamental no processo de desenvolvimento humano, tendo em vista que é compreendida como um conjunto de esforços empreendidos para coordenar e mediar os diferentes setores da escola. Ou seja, a gestão escolar não se limita à organização administrativa da escola, ela deve estar alinhada ao projeto da coordenação pedagógica quando se trata em comprometer-se com o desafio de fazer avançar os olhares e as concepções de aprendizagem que orientam o trabalho pedagógico da equipe como um todo, - estabelecendo com os membros da equipe a organização dos horários e rotinas que estruturam o espaço e o tempo das crianças; orientando sobre as formas de interação das crianças com os adultos e crianças de diferentes faixas etárias nos diferentes momentos da rotina; proporcionando condições materiais para que os membros da equipe possam diversificar as experiências de exploração, vivências e brincadeiras das crianças; avaliando os contextos de aprendizagem e desenvolvimento proporcionados para as crianças e principalmente, criando na escola espaços para a reflexão e aprendizagem dos membros da equipe que atuam direta e indiretamente com os bebês e com as crianças pequenas. (OLIVEIRA, 2008)

\section{Considerações finais}

A constituição deste trabalho guiou-se pela intenção em responder de que maneira os processos de formação continuada podem ampliar a compreensão dos professores sobre a organização do tempo e das rotinas das crianças que frequentam a escola da infância. Nesse sentido, pontuamos alguns desencontros entre o propõe a legislação em vigor e as pesquisas que defendem o processo educativo como possibilidade de desenvolvimento pleno na 
infância. Assim, articulamos as contribuições da Teoria Histórico Cultural, para pensarmos a organização dimensões educativas - tempos, espaços, materiais e relações sociais - tendo em vista que as ações docentes precisam estar embasadas teoricamente, caso contrário, tais ações se pautam no senso comum. Diante disso, a formação continuada foi estruturada de modo a provocar a aproximação das professoras com a teoria, promovendo a participação ativa nos momentos de estudo, a reflexão a partir do contexto de trabalho e a partilha de ideias entre os pares.

Ainda que este estudo apresente apenas um recorte da pesquisa em andamento, os dados analisados - por meio dos discursos das professoras envolvidas- revelaram a importância da formação continuada para a apropriação teórica dos professores e os estudos compartilhados nos momentos de formação gradativamente concretizaram-se em práticas potencialmente humanizadoras, ao mesmo tempo em que contribuíram para o desenvolvimento profissional das professoras parceiras nesta pesquisa.

\section{Referências}

BARBOSA, Maria Carmen Silveira. Por amor e por força: rotinas na educação infantil. Porto Alegre: Artmed, 2006.

BATISTA, Rosa. A rotina no dia-a-dia da creche: entre o proposto e o vivido.

Florianópolis, SC, 1998. 183p. Dissertação (Mestrado em Educação) Universidade Federal de Santa Catarina, 1998.

BRASIL. Ministério da Educação. Diretrizes Curriculares Nacionais para a Educação Infantil. Resolução CNE/CEB n.5, de 17 de dezembro de 2009. Brasília: MEC, CNE/CEB, 2009.

BRASIL. Ministério da Educação. Base Nacional Comum Curricular, BNCC. Brasília, DF: MEC, 2017.

FRAGO, Antonio Viñao. Historia de la educación y historia cultural: possibilidades, problemas, cuestiones. Revista Brasileira de Educação, Rio de Janeiro, edição nº306, (p. 6382), 1995. Disponível em: http://educacao.uniso.br/pseletivo/docs/FRAGO.pdf Acesso em 07/02/2020.

GOMES, Marineide de Oliveira. Formação de professores na Educação Infantil. $2^{\mathrm{a} e d . ~ S a ̃ o ~}$ Paulo: Cortez, 2013.

JESUS, Degiane Amorim Dermiro de; GERMANO, Jéssica. A Importância do planejamento e da rotina na educação infantil. In: Anais da II Jornada de Didática e I Seminário de Pesquisa. Docência na Educação Superior: Caminhos para uma práxis transformadora. (p. 2940), 2013. CEMAD. ISBN. 978.85.7846.211-6.

MARTINS, Lígia Márcia. O desenvolvimento do psiquismo e a educação escolar: contribuições à luz da teoria histórico-cultural e da pedagogia histórico-crítica. Campinas, SP. Autores associados, 2013. 
MELLO, Suely Amaral. Linguagem, Consciência e alienação: o óbvio como obstáculo ao desenvolvimento da consciência crítica. Marília: Unesp-Publicações, 2000.

. As práticas educativas e as conquistas de desenvolvimento das crianças pequenas. In: RODRIGUES, Elaine; ROSIN, Sheila Maria. Infância e práticas educativas. Maringá: Eduem, 2007. (p. 11- 22).

A especificidade do aprender na pequena infância e o papel do/a professor/a. In: MAGALHÃES Cassiana; EIDT, Nádia. (Org.). In: Apropriações teóricas e suas implicações na Educação Infantil. $1^{a}$ ed. Curitiba: CRV, 2019. (p. 93-108)

\& FARIAS, Maria Auxiliadora. A escola como lugar da cultura mais elaborada. Revista Educação, Santa Maria, v. 35, n. 1, (p. 53-68), jan./abr. 2010. Disponível em: https://periodicos.ufsm.br/reveducacao/article/view/1603. Acesso em 13/03/2020.

GIROTTO, Cynthia Graziela Simões et al. Planejamento a ação docente: Para o máximo desenvolvimento na infância. In.: COSTA, Sinara Almeida \& MELLO, Suely Amaral (org). Teoria histórico-Cultural na educação Infantil: conversando com professoras e professores. 1. ed. Curitiba: CRV, 2017. (p. 219-230)

NIGITO, Gabriela. Tempos institucionais, tempo de crescimento: a gestão do cotidiano dos pequenos, dos médios e dos grandes na creche. In: BONDIOLI, Anna. (Org.). O tempo no cotidiano infantil: perspectivas de pesquisa e estudo de caso. Trad. Fernanda L. Ortale e Ilse Paschoal Moreira. São Paulo: Cortez, 2004. (p. 43-95).

OLIVEIRA, Zilma Ramos de. A gestão pedagógica das instituições de educação infantil. In: GUIMARÃES, Célia Maria.; RIBEIRO, Arilda Inês Miranda (Orgs.). Gestão Educacional: questão contemporâneas. Araraquara, SP: Junqueira \& Marin; Presidente Prudente, SP: FUNDACTE, 2008. (p. 121-146)

PACHECO, Alessandra Brandolim et al. A pesquisa como espaço de formação. In: KRAMER, Sônia; NUNES, Maria Fernandes; CARVALHO, Maria Cristina (orgs.) Educação Infantil: formação e responsabilidade. $1^{\text {a }}$ ed. Campinas, SP. Papirus, 2013. (p. 297-307)

PRIETO, Mariana Natal. A organização do tempo em escolas de educação infantil: contribuições para o processo de humanização na infância. 2016. p. 157. Dissertação (Mestrado em Educação) - Universidade Estadual Paulista/UNESP, Marília, 2016.

PIRES, Adriane Regina Scaranti; MORENO, Gilmara Lupion. Rotina e escola infantil: organizando o cotidiano de crianças de 0 a 5 anos. Disponível em: https://educere.bruc.com.br/arquivo/pdf2015/15902_9267.pdf . Acesso em: 09/05/2020.

RIBEIRO, Aline Escobar Magalhães. As relações na escola da infância sob o olhar do enfoque histórico cultural. 2009. 181p. Dissertação (Mestrado em Educação) - Universidade Estadual Paulista/UNESP, Marília, 2009.

ROMANOWSKI, Joana Paulin; ENS, Romilda Teodora. As pesquisas denominadas do tipo "estado da arte" em educação. Diálogo Educacional, Curitiba, v. 6, n.19, p.37-50, set./dez. 2006.

SILVA, Greice Ferreira da Silva. A participação das crianças na organização da rotina. In.: COSTA, Sinara Almeida; MELLO, Suely Amaral (org). Teoria Histórico-Cultural na Educação Infantil: conversando com professoras e professores. $1^{\text {a }}$. ed. Curitiba: CRV, 2017. (p. 141-152). 
TEIXEIRA, Sônia Regina; BARCA, Ana Paula de Araujo. Teoria Histórico-Cultural e Educação Infantil: concepções para orientar o pensar e o agir docentes. In.: COSTA, Sinara Almeida; MELLO, Suely Amaral (org). Teoria histórico-Cultural na educação Infantil: conversando com professoras e professores. 1. ed. Curitiba: CRV, 2017. (p. 219-230)

VIEIRA, Analucia de Morais. Produções de espaço - tempo no cotidiano escolar: um estudo de marcas e territórios na Educação Infantil. 2000. 155p. Dissertação (Mestrado em Educação) Universidade de Campinas/UNICAMP, Campinas, 2000.

VYGOTSKI, Lev Semenovich. Las crisis de los siete años. In: Obras Escogidas IV: problemas de la Psicologia Infantil. Madrid: Visor, 1996. (p.377-386).

Génesis de las funciones psíquicas superiores. In: Obras Escogidas III: Historia del desarrollo de las funciones psíquicas superiores. Madrid: Visor, 2000. (p.139-168).

A psicologia e o professor. In: Psicologia Pedagógica. Porto Alegre, RS: Artmed, 2003. (p. 295-306).

Quarta aula: a questão do meio na pedologia. In: Sete Aulas de L.S. Vigotski: sobre os fundamentos da Pedologia. Tradução e Organização de Zoia Prestes e Elizabeth Tunes. 1.ed.Rio de Janeiro: EPapers, 2018. (p.73-92)

Recebido em: fevereiro/2021.

Aprovado em: abril/2021. 